\title{
Conferences/Seminars
}

\section{The Seminar on "The Sunnah and its Methodology for Structuring Knowledge and Civilization" Amman, Jordan}

Dhu al Qidah 15-18, 1409/June 19-22, 1989

The Seminar on "The Sunnah and its Methodology for Structuring Knowledge and Civilization" was held as the Seventh General Assembly of the Jordanian Royal Academy for Islamic Civilizational Research (The Aal Al-Bayt Foundation), and in coopertion with the IIIT of Washington, D.C. One hundred and twenty six Muslim scholars took part in the Seminar.

\section{The Discussions:}

The Seminar revolved around three axes. The first included an overview of previous Sunnah conferences and seminars. The second encompassed current efforts in compiling and serving the Sunnah in the spheres of publication, exacting research, explanation, epitomization; and in whatever pertains to compilation, indexing, and the utilization of computers in classification. The third axis, which included the presentation of nine papers with two commentaries on each, dealt with the main topic of the Seminar, namely, the explication of the Sunnah, the methodology of utilizing it in argumentation, and the precepts and methods involved therein; the means of comprehending it and dealing with it in the past and present; and the refutation of the allegations made against it. The presentations and commentaries spoke of the Sunnah as a source of knowledge, Islamic legislation, and education-emphasizing its role in international law and its function in erecting the Ummah's cultural/intellectual edifice, and civilization.

In addition, three reports on the use of computers in the service of the Sunnah were presented at the Seminar. The participants were also informed of the efforts of a number of foundations actively serving the Sunnah in different parts of the world.

There were widespread discussions in the Seminar emphasizing the importance of the noble Sunnah, since it is the Qur'an and the Sunnah which constitute the two main sources of Shariah. Together, both sources should be adopted as the cornerstone in building contemporary Islamic life, and as a foundation for the Islamization of the Humanities and the Social Sciences that would depend on two sources of knowledge: revelation and reason. 


\section{Recommendations:}

The Seminar arrived at the following recommendations:

\section{First:}

There is a dire need to study previous conferences and seminars on the Sunnah and Seerah, as well as all effort exerted in their service in order to build upon it and facilitate its utilization.

Despite the appreciation of the efforts exerted in the first two axes of this Seminar, the need exists to complete the survey of all conferences, seminars, and other efforts exerted; and to study their activity according to methodological criteria that would realize the goals of this process. Therefore, the Seminar recommends that the Royal Academy for Islamic Civilizational Research, in cooperation with the IIIT, undertake the preparation of this study, and the publication and dissemination of an analytic index of all these efforts to researchers and scholars.

\section{Second:}

Although the Seminar appreciated efforts exerted illustrating the legal authoritativeness of the Sunnah, and refuting doubts cast against it in the past and present, it called for a focus on the issues related to the understanding of the Sunnah and an illustration of its role, along with that of the Qur'an, in building contemporary Islamic life. This focus starts with the Islamic conception of the issues of existence (the universe, life, and man). It involves values and ethical, educational, intellectual, cultural, and social views which constitute the foundation of the Islamic economic and political system. The focus ends with a well-integrated edifice of human civilization that deals with the realities of life and interacts with the challenges of the age. This is to be coupled with an emphasis on the Islamization of the Humanities and the Social Sciences so as to realize, by the Will of Allah (SWT), the Ummah's renaissance and progress. The Seminar also stressed that forthcoming Sunnah and Seerah conferences and seminars should strive towards the realization of these goals in accordance with a well-integrated, comprehensively and objectively structured, scientific plan of action that would be prepared by a team of Islamic scholars specializing in various fields of knowledge. The concerns of this plan should include: 
1. The elucidation of the Sunnah's distinctive approach in acquiring knowledge and building civilization.

2. The meticulous compilation of the noble ayät and illustrious Prophetic traditions (Hadiths) that deal with Allah's laws regarding the universe, man, and society; and their objective classification under all the fields of knowledge.

3. The devotion of special attention to comparative studies, and the accomplishments of human civilization in various fields of knowledge in order to reveal the preeminence of the Sunnah.

4. The preparation of a comprehensive classification of the proposed research in all fields of knowledge.

5. The recommendation of the research approach and methodology required for the implementation of the plan in a way that would safeguard the uniqueness of Islamic Sciences, and firmly establish the foundation of Islamic Epistemology which endorses revelation and reason as the two sources of knowledge.

The Seminar also recommended that the Royal Academy for Islamic Civilizational Research and the IIIT follow up the implementation of these recommendations.

\section{Third:}

The Seminar emphasized that the process of utilizing the Sunnah in order to realize the aforementioned goals required that special attention be devoted to the following:

1. The continuation of efforts aimed at properly researching, publishing, utilizing, and providing easy access to the Sunnah books which are still in manuscript form.

2. The completion of the encyclopedias of the Hadith, the Sciences of Hadith, and the narrators and authentic sources of Hadith.

3. The preparation of tables of contents and objective, analytic indices that are arranged in accordance with the words of the Sunnah and under topic headings-particularly those appearing in modern sciences: the Humanities, the Social Sciences, and the Physical Sciences. 
4. The extraction and interpretation of all Hadiths after carefully scrutinizing the ascription (isnad) of each Hadith [i.e., the uninterrupted chain of authorities on which it is based] and its text according to stipulated scientific criteria; and the publication of the results of this effort on a wide scale through all available means.

5. The creation of a database bank for the Sunnah, Seerah, and the Qur'an which would provide all possible services to researchers and scholars.

6. The preparation and training of scientific cadres needed to complete these projects; and the selection of the highest of standards for their implementation due to their importance and the pressing need for them.

\section{Fourth:}

In order to realize the aforementioned ends, the Seminar recommended that Jordan's Royal Academy for Islamic Civilizational Research call upon the foundations actively engaged in the service of the Sunnah (through exacting research, classification, organization, and the utilization of computers) to attend a seminar to discuss coordination and cooperation between them. This cooperation would involve a comprehensive plan with projects to be allocated to these foundations for development and implementation. Each project would carry the name of the foundation implementing it.

The meetings of these foundations for reviewing the plan and its implementation phases would become periodical. The Royal Academy for Islamic Civilizational Research will cooperate with the IIIT, and all other foundations and agencies assisting in the implementation of this recommendation.

\section{Fifth:}

The Seminar recommended that great care be devoted to the teaching of the Sunnah and Seerah in universities and at various educational stages in Arab and Islamic countries in particular. This should be done in a way that would illustrate the role of the Sunnah in the formulation of Islamic life, and reveal its great contribution to various fields of knowledge. 
1. The elucidation of the Sunnah's distinctive approach in acquiring knowledge and building civilization.

2. The meticulous compilation of the noble ayāt and illustrious Prophetic traditions (Hadiths) that deal with Allah's laws regarding the universe, man, and society; and their objective classification under all the fields of knowledge.

3. The devotion of special attention to comparative studies, and the accomplishments of human civilization in various fields of knowledge in order to reveal the preeminence of the Sunnah.

4. The preparation of a comprehensive classification of the proposed research in all fields of knowledge.

5. The recommendation of the research approach and methodology required for the implementation of the plan in a way that would safeguard the uniqueness of Islamic Sciences, and firmly establish the foundation of Islamic Epistemology which endorses revelation and reason as the two sources of knowledge.

The Seminar also recommended that the Royal Academy for Islamic Civilizational Research and the IIIT follow up the implementation of these recommendations.

\section{Third:}

The Seminar emphasized that the process of utilizing the Sunnah in order to realize the aforementioned goals required that special attention be devoted to the following:

1. The continuation of efforts aimed at properly researching, publishing, utilizing, and providing easy access to the Sunnah books which are still in manuscript form.

2. The completion of the encyclopedias of the Hadith, the Sciences of Hadith, and the narrators and authentic sources of Hadith.

3. The preparation of tables of contents and objective, analytic indices that are arranged in accordance with the words of the Sunnah and under topic headings-particularly those appearing in modern sciences: the Humanities, the Social Sciences, and the Physical Sciences. 
4. The extraction and interpretation of all Hadiths after carefully scrutinizing the ascription (isnad) of each Hadith [i.e., the uninterrupted chain of authorities on which it is based] and its text according to stipulated scientific criteria; and the publication of the results of this effort on a wide scale through all available means.

5. The creation of a database bank for the Sunnah, Seerah, and the Qur'an which would provide all possible services to researchers and scholars.

6. The preparation and training of scientific cadres needed to complete these projects; and the selection of the highest of standards for their implementation due to their importance and the pressing need for them.

\section{Fourth:}

In order to realize the aforementioned ends, the Seminar recommended that Jordan's Royal Academy for Islamic Civilizational Research call upon the foundations actively engaged in the service of the Sunnah (through exacting research, classification, organization, and the utilization of computers) to attend a seminar to discuss coordination and cooperation between them. This cooperation would involve a comprehensive plan with projects to be allocated to these foundations for development and implementation. Each project would carry the name of the foundation implementing it.

The meetings of these foundations for reviewing the plan and its implementation phases would become periodical. The Royal Academy for Islamic Civilizational Research will cooperate with the IIIT, and all other foundations and agencies assisting in the implementation of this recommendation.

\section{Fifth:}

The Seminar recommended that great care be devoted to the teaching of the Sunnah and Seerah in universities and at various educational stages in Arab and Islamic countries in particular. This should be done in a way that would illustrate the role of the Sunnah in the formulation of Islamic life, and reveal its great contribution to various fields of knowledge. 


\section{Sixth:}

The Seminar commended the great scientific efforts of the Royal Academy for Islamic Civilizational Research in the spheres of Islamic Sciences and Civilization and expressesed its appreciation of the research, studies, and indices produced in record time and with exceptional proficiency.

The Seminar also appreciated the efforts of the Academy in the spheres of cooperation and coordination between the foundations and the centers active in the fields of Islamic Studies as well as the diligence of the IIIT in the field of the Islamization of Knowledge and the founding of the humanities and the social sciences on Islamic bases.

\section{A Final Comment:}

This Seminar constitutes a turning point in the trends of contemporary Islamic Thought. For the first time, Muslim intellectuals are breaking out of the obsolete sophistic framework of utilizing the Sunnah solely for the purpose of argumentation, and are heading towards open vistas for presenting the illustrious Sunnah and Seerah as legitimate sources of knowledge on which to found the Humanities and Social Sciences. By flowing from Divine Revelation, contemporary knowledge would acquire the qualitative dimension it lacks and begin to focus attention on the correct example set by the noble Sunnah of the Prophet Muhammad (ȘAS).

Realizing that the technical aspects generally treated by Muslim scholars in the past and present, have been exhaustively researched, investigated, and written about, the Seminar's participants have asserted the present need for the utilization of the Sunnah and Seerah as sources of sound thought, true knowledge, moral culture, and civilization. By focusing on the means of accomplishing this noble task, the Seminar has opened the way for Muslim intellectuals to enrich this highly important yet long neglected dimension. 